\title{
A Systematic Approach to Quality Assurance Tourism Product Development: Theory and Practice
}

\author{
Ogneva Svetlana Vasilievna ${ }^{1}$ \\ ${ }^{1}$ Institute of Tourism and Hospitality (Moscow) (branch) of Federal State, Budgetary Educational Institution of \\ Higher Professional Education, Russian State University of tourism and Service, Moscow, Russian Federation \\ Correspondence: Ogneva Svetlana Vasilievna, Kronstadt Blvd, D. 32-A, 125485, Moscow, Russian Federation. \\ E-mail: sogneva.s@bk.ru
}

\author{
Received: February 8, 2015 Accepted: February 18, 2015 Online Published: March 16, 2015 \\ doi:10.5539/ass.v11n7p305 URL: http://dx.doi.org/10.5539/ass.v11n7p305
}

\begin{abstract}
The article describes the theoretical basis of the system approach, given the international standards, the use of which allows to apply a systematic approach to quality assurance tourism product. The following aspects of quality of tourist services: a systematic approach, risk management and information, standardization and quality evaluation of the quality monitoring. Presents a practical implementation of a systematic approach in the tourist regions of Russia. Studies have allowed us to justify the creation of a unified methodological support of quality monitoring, the safety of tourists, tourism development, implementation of risk management systems and suppliers, the need to increase the responsibility of providers of tourism services. The adoption of measures based on the system approach, aimed at improving the quality of state regulation of tourism.
\end{abstract}

Keywords: tourism, competitiveness, system approach, risk management, quality, safety, state regulation

\section{Introduction}

Tourism is an important component of innovative development of Russia, because it can have a significant positive impact on the economic development of the country (Order of the Government of the Russian Federation from November 17, 2008 \# 1662-r). Russian tourism requires close attention from the state. In the ranking of countries in the world in 2013 in terms of the competitiveness of the travel and tourism sector Russia took 63 place (WEF: The ranking of countries in the world in terms of the competitiveness of the travel and tourism sector, 2013). Strong competitive factors in Russia are rich natural and cultural resources, air traffic infrastructure and telecommunications infrastructure. In turn, a significant negative influence is due to the quality of land transport infrastructure, weak business environment and low price competitiveness. A very low safety rating (113th place). This takes into account crime, police responsiveness, the number of accidents per 100 thousand populations. A low assessment (134th place) was given to the environmental situation. Russia is at the end of the rating (123 place) in terms of "policy and regulation" that takes into account the right of ownership, visa procedures, transparency of government policies, etc. Russia's position improves very slowly since 2009 (59th place). Russia's share in world export remains very low, it was in 2013 about one percent. (Vazovskaya et al., 2014), despite a series of measures by the tourism authorities related to the use of program-target method of management. For example, the adoption and implementation of the federal program, regional and municipal targeted programs for tourism development, changes in legislation (the introduction of financial guarantees for tour operators), and others. The travel year 2014 was marked by the bankruptcy of many tourist companies and confirmed the failure of government regulating measures in tourism (RIA News), the need to improve legislation on tourism (News PCT, 2014). Problems encountered in the tourism industry, were the basis for the study conducted by the author of this article, these studies aimed at the developing of recommendations for tourism controlling authorities. The application of recommendations based on the use of a systematic approach will improve the efficiency of their decisions in the field of quality and safety regulation of tourist services.

\section{Method}

The information base for the study was the Russian federal and regional regulatory legal acts, tourism development programs, international standards in the field of quality management, materials of research papers on the topical issues of tourism, the practice of a systematic approach and individual elements of the system in tourist areas. 
The method of the study included the study the explanation of the role of the quality and safety of tourist services in improving its competitiveness, the approach to the management of tourist service as a project; the allocation of functional areas of the project, reflecting the specificity of tourist services, the proof of the necessity of tourists' risk management, and developing a system of risk management by tourist organizations. To prove the features of the systematic approach to the quality management of tourist service we have been studied international standards and recommendations for their use in various areas; Russian national standards covering such aspects as project management, risk management, quality management, and customer satisfaction. The next step was to study the system of regulation of the requirements for quality and safety, mandatory requirements for the information provided to the tourist. We gave an explanation of the role of information in tourists' decision-making about a trip. We studied the law tourist regions and the practical application of some elements of the system in the tourism sector. We made an analysis of the recommendations of the Russian Union of tourist industry to improve the performance of tourist organizations, and to increase their responsibility. The last step of the research was to develop recommendations for the tourism authorities.

\section{Results}

\subsection{The Quality and Competitiveness}

The researchers of the problems of development of Russian tourism and competitiveness problems think that one of the most important factors of competitiveness is the quality of tourist services (Goldin, 2002; Minko \& Krichevsky, 2004). The service quality is created in the process of its delivery, and is the result of the efforts of all service providers, who are included in the tourist product. For this process we need information, infrastructure, human resources, technology, standards, and objects of tourist show. All of these factors affect the quality of the service perceived by the consumer. The basis of the quality is the safety of the tourist's services for the tourist. The tourist, assessing the extent of the conformity of the quality of tourist's services with his own needs, assesses the presence of the conditions of safe stay at a particular territory. The quality and safety of the tourist's service is a complex subject to control, as in the creation of the service involves a large number of suppliers hotels, transport companies, catering companies, travel agencies, tourism organizations and others, depending on the type of tourist's service. The risk of not receiving a service of the quality ordered by the tourist is great, and the more suppliers and intermediaries we have, the higher is the risk, therefore, control actions should be proactive. An important factor of competitiveness is, of course, the price of the service. The high quality of the services even with price competition is the predominant factor of competitiveness. In economically developed country with a high competition, quality is the basis of the business.

\subsection{The Quality of Tourist Services and Risk Assessment}

Tourist's service can be considered as a project, as a set of interrelated activities, aimed at creating a unique integrated tourist's product in terms of time and resource constraints. The project is implemented by a set of scheduled, interrelated and interdependent processes (ISO 10006: 2003), i.e. in a system. We should highlight such functional areas of the project (GOST R 54869-2011) as: risk management, project supply management, quality management, project information sharing and others. These functional areas are inherent in tourist's service, as a project. Risk management includes risk assessment techniques. In world practice we use various methods for risk assessment (ISO / IEC 31010: 2009). Risk assessment is a structured process in which the concerned people identify the ways to achieve their goals; they analyze the consequences and likelihood of hazardous events for making decisions. Risk assessment allows us to answer the following questions:

- What dangerous, adverse events with tourists and providers may occur and their causes (the identification of dangerous events);

- What are the consequences of these events?

- What is the likelihood of their occurrence?

- What factors can reduce negative consequences or reduce the likelihood of dangerous situations.

Risk assessment of tourist services for the consumer from the government, service providers will minimize the risks of the service providers and create the conditions for an informed choice of tourism product and the country to visit by the tourist. The basis for the assessment of the risk and its consequences, primarily for the life and health of the tourist, is the information about various events (war, terrorism, sanitary, epidemiological) in tourist's areas, about terms and conditions of providing tourist's services. It seems logical for tour operators and providers of tourist's services to create a unified system of project risk management - a complex tourist's service (ISO 31000: 2009), the development of risk management programs for tourists using the national standard of management of the project program (GOST R 54871-2011). 


\subsection{Quality and Systematic Approach to Quality Management in Tourism}

Theoretical positions of systematic approach to quality management are summarized by the International Organization ISO (ISO) in the international standards, which include cross- sectoral requirements for quality management systems (GOST R 54536-2011) and can be applied by any organizations, such as business and management and control bodies (ISO 9001, ISO 9004). For the adaptation of ISO 9001 standard to the type of the economic activity, ISO offers recommendations. For example, for state and municipal control bodies - the standard ISO 18091: 2014, for the control bodies - ISO / IEC 17020-2012. For small organizations the Technical Committee ISO / TC 176 for Standardization published recommendations (Advice from ISO / TC 176 "ISO 9001 for small businesses", 2010), which are accepted in Russia as a national standard (GOST R 54985- 2012). All international standards in management system are used in Russia. The insurance of the quality of the tourist's product is possible by using a systematic approach, i.e. the creation of a quality management system based on the process approach ISO 9001: 2008 with including in the system the process - risk management according to ISO 31000: 2009. The quality management system, which is created for the quality management of the complex tourist's service, presupposes a set of elements:

- Responsibility, including the responsibility of particular services;

- Resources (financial, human, infrastructure, display objects);

- Interrelated processes of the life cycle of tourist's service;

- Techniques - how to implement the processes (documents, including standards for services and procedures, instructions on the processes);

Monitoring process, analysis and improvement, including the management of nonconforming service and the measurement of tourists' satisfaction.

Process approach includes managing interrelated activities, undertaken by Tourism Organization, providers of certain types of services, included in a complex tourist's product and tourism authorities. In the system of quality management based on a process approach we applied eight well-known principles (Quality management principles, 2012), among them, the principle of "mutually beneficial relationships with the providers". Any organization of tourism industry from the position of the system approach builds its system for controlling the providers, and here we cannot do without government interference, as it is only legally possible to establish the distribution of responsibility for the quality of the tourist's product, including product's and tourist's safety.

\subsection{Regulation and Evaluation of the Quality of Tourist Services}

The quality of the services of each provider included in the tourist's product is regulated by a system of normative acts, including its own service standards. Safety requirements for services, as a basis of quality, are uniform and mandatory for all companies - providers of services, and the regulation of these requirements is implemented by laws, services rules and technical regulations. Consumer characteristics of the service supplement the safety characteristics and generate the necessary service quality for tourists. To this end, tourists organizations use in their activities national standards and classifications, international standards, including standards for management systems, voluntary to use (Federal law on technical regulation, 2002).

The implementation of the mandatory normable requirements is monitored by the control bodies according to the results of state supervision, and annually (2012-2013 years) reports are issued on "Protection of Consumers' Rights". The report reveals the results of the inspection of tourists' organizations to fulfill legal requirements for the completeness and quality of the information provided to the tourists. The fulfillment of the voluntary requirements is estimated by the consumer of the services. In international practice for this purpose, they use national indices of consumer satisfaction. In Russia, for assessing the quality of tourists' services in 2014 they introduced an index "The level of satisfaction of the citizens of Russian Federation with the quality of tourism services" (Resolution of the Government of the Russian Federation from 15.04.2014). To work with consumer complaints ISO offers the international community a set of standards. Personal safety of the tourist in large part is due to his understanding of the risk degree while using the tourist's service, which is based on the information provided by the tourists' organizations, and other members of the security management system. A complete, reliable, timely information, obtained by the tourist - is a pledge of conscious tourist's attitude to the travel, especially when in traveling to countries where he may experience a variety of threats, so building an effective information management system for tourists, both at the international level, and nationally is an important and topical issue. Complete and reliable information, received by service providers and tourism authorities - is a basis for management decisions, aimed at improving the quality and safety of tourist's product and competitiveness of tourism. Improving informational ensuring of tourists is an object of study for many researchers. Researches (Sharafutdinova, 2010) were implemented. They gave an impetus to the creation of 
regional and municipal tourist information centers (TIC), which subsequently will create a single information system on the territory of Russia. The main role of the centers is the promotion of tourists' products in a particular territory. But we believe that their functions can be extended by transferring of TIC processes of measurements of tourists' satisfaction with the services quality, creating a basis for the emergence of regional components of the national index.

\subsection{Quality and Monitoring}

In Russia, there is a system of situational respond to problems accruing to tourists, but we need a proactively impact. Problems of tourism development, quality and safety assurance of tourists' products, tourists' safety requires the implementation of system solutions, for which it is necessary to build a clear information interaction of all the participants of the safety ensuring system in tourism, all of its subsystems and levels, for the collection and analysis of data, on the state of tourism development in the system of monitoring observation. Creating a system of safety monitoring, which includes the collection of comprehensive information, primarily accidents with tourists, and identifying the systemic causes of these incidents, information on monitoring results, and the identified problems in the activities of tourist's firms and the assessment of tourists' satisfaction is the primary task of the state. The need for monitoring the safety of the tourists is recognized by all, including the executive authorities in the regions. In the Doctrine of tourism safety in the Russian Federation, developed by Pisarevsky EL (Pisarevsky, 2011), highlighted key areas of legal and administrative activities to ensure the safety of the tourists, among them:

- Prediction, identification, analysis, evaluation of security risks, development and application of a set of measures for their prevention and elimination, localization and neutralization of the consequences of threats;

- Organization of an effective public-legal protection of the rights and legitimate interests of the tourists;

- Improving the quality and accessibility of public services in the field of tourism security, improving the efficiency of monitoring and supervising authorities;

- To ensure a coordinated functioning and interaction of regional and municipal authorities;

- Assistance in the reparation of damages for the tourists, who were affected by security threats and (or) the consequences of their occurrence;

- The implementation of measures to improve the culture safety in tourism and other.

Activities on tourism safety insurance are possible if there is a monitoring system.

Monitoring, in a broad sense - is an activity of monitoring (tracking) certain objects or phenomena. For monitoring the processes we need:

- To establish the criteria by which need to make a monitoring (assessment) of the processes of the quality system,

- To determine what data should be collected in order to understand: how well the processes are going on,

- To establish who will collect data, and from what sources,

- Clearly identify for whom data is collected,

- To determine in what form we should make decisions based on the results of processes monitoring.

The monitoring system in tourism may include several sub-systems: security monitoring, monitoring of tourists' satisfaction, monitoring of regional measures to tourism development, carried out in the frameworks of legislation and tourism development programs and their effectiveness.

The first steps in this direction exist, in the form of annual statements and reports to the Government of Russia. But on the whole the monitoring system is not formed.

\section{Discussion}

The complexity of managing the quality of the services depends on the degree of touchableness of the service, and on its certainty. The less tangible is the service, the greater is the role of the information provided for the tourist. Quality - is information about the properties of objects (Shadrin, 1996). Availability of information allows the tourist to minimize his risks in the tourist trip. For the consumer the quality of services is associated with the quality of information, at the same time the risk for the tourist remains, so the information should have such characteristics as completeness, reliability, timeliness, stability of information. Information requires management through the creation of information system in which a high role is given to tourism management bodies, because of the features of the tourist's service itself. Building an information system for informing 
tourists is a task of the state, being an area of state responsibility. Responsibilities in the field of informational support of tourists and the federal tourism authorities are imposed by law, on the persons carrying out tourist activities, on other providers of services in the tourism sector, and on the federal executive authorities (Ministry of Foreign Affairs of Russia, the Federal Service, Rosturizm, Roshydromet, MVD, FSB and others), the authorities of the Russian Federation and local authorities. Each participant of the information management system annually prepares his own report on the status of the fixed direction of the activities. Fragmentation of information reduces the effectiveness of these bodies. The current informing of tourists about the threat to their security (tourists) in the country (place) of temporary stay, including publishing relevant messages in state public media is carried out by a government body of Tourism - Rosturizm - Federal Agency for Tourism. For strategic and medium-term solutions in the field of tourism, the Government of Russia and Rosturizm need full information about the state of tourism, collected on the basis of a united methodological basis.

In some regions, there are laws on tourism, on the basis of which they annually prepare regional reports on the development of tourism based on the monitoring of the tourism development. It follows that there is an understanding in business, tourism authorities, of the need for a systematic approach to the evaluation of the development of tourism, as well as quality and safety evaluation. In the regions of Russia, for example, in the Arkhangelsk, Kostroma, Saratov regions reports on the state of tourism development are made annually in order to create an information-analytical base for the organization of an interaction of executive authorities, of all levels, of local government municipalities, the subjects of the tourists' industry, scientific -research, educational, public and other organizations, who have activities in the field of tourism. Reports are the basis for determining the priority directions of development of tourists' activity, and the development of a set of measures to improve the legal regulation and governance in the field of tourism in these areas (Resolution of the government of the Arkhangelsk region from August 21, 2014 \# 337; The law of the Samara region from 14.06.2011 \# 51-GD; The decree of the Administration of the Kostroma region on October 8, 2013 \# 403-a).

Reports are result of monitoring according to a number of indicators, which are not uniform from the methodological point of view. A report on the development of tourism - is the first step toward building an integrated monitoring system in Russia.

A systematic approach proposed by the ISO in the series of standards 9000 , today is undergoing a number of changes. In 2015, they plan to release a new revised standard ISO 9001. The content of the amended standard includes such elements of quality management system as, management (processing) of risks, management of external supplies, performance evaluation.

The application of ISO standard of the new version by the travel agencies and their contractors is aimed at ensuring credibility of the tourists' services, provided by the organization, at increasing tourist's satisfaction.

\section{Conclusions}

Analysis of the theory and the practice of implementation of a systematic approach, allows drawing some conclusions on the application of a systematic approach to quality control and safety of tourists' services, to develop some suggestions for tourism authorities.

System management of tourism in Russia is gradually taking shape. The elements of this system are gradually formed. From our point of view, the slowest is the process of formation of the interaction with service providers, such as transport companies, or with foreign partners. The implementation of users' risk management system in the activities of tourists' organizations also lags behind. Risk management, including consumer risks, is another new and actual direction associated with quality management of tourist services. Due to the large number of factors affecting the quality of both objective and subjective, the risk increases, both for the providers of tourists' services, and for the consumers of these services. In this regard, in the management of the quality of tourist services it is necessary to consider the ways of influencing upon consumer risks.

According to GOST R ISO 9004-2010 for the sustained success of an organization we should regularly monitor, measure, examine and analyze their effectiveness of our activity. The effectiveness of the activity of tourism authorities lies in the effectiveness of the decisions made on tourism development (increasing the flows of the domestic and entrance tourism), and the efficiency and quality of the decisions depends on the quality of the information obtained, from the efficiency of the process of informational support of the controlling bodies.

The monitoring system of information on the development of tourism, on the quality and safety of tourists' services is only being formed. It is proposed to establish the system of monitoring in tourism in the form of several subsystems:: security monitoring, monitoring of tourists' satisfaction, monitoring of regional measures to tourism development, carried out in the frameworks of legislation and tourism development programs and their 
effectiveness. Researchers of security problems of tourism believe, as well as the author of this article, that the safety monitoring of tourism is one of the directions of state policy realization in the field of tourism safety (Pisarevsky et al., 2011).

In this article, we only concisely voiced the idea of structuring information in subsystems; further researches in this direction are needed. The monitoring system should be provided organizationally and methodically, which requires a whole series of works.

On the basis of monitoring an annually independent State report should be submitted to the Government, it should be about the development of tourism in the Russian Federation on the basis of regional reports. Data analysis of the report is the basis for assessing the effectiveness of measures in the field of tourist's safety, security and quality of the tourists' product, made by the institutions of tourism management, and a basis for the development of new and the correction of the existing regulatory effects in order to increase the competitiveness of Russian tourism. Currently, the information on tourism is contained in the State report on the development of culture, a public report on the protection of consumers' rights and it is not systemic, but fragmented. For the first time the basic provisions for monitoring the quality were published by the author of this article in 2011 (Ogneva, 2011). Today the Government of Russia made concrete steps in this direction: it made an appropriate order on the measures to implement the Strategy of tourism development until 2020 (A Decree of the Government of the Russian Federation from 31.05.2014 N 941-p), which provides for the granting of an annual report on the status and development of tourism in the Russian Federation (Order of the Government of the Russian Federation of 11.11.2014 N 2246-p).

Next we need to develop the structure of the report that best meets its objective - the development of Russian tourism. To improve the efficiency of the tourism authorities, to prepare the report we must clearly describe the cooperation of all parties in the administrative regulations of interaction, to fulfill the authorities' functions by guidance documents, including monitoring.

Monitoring, information provision of the tourist and tourism authorities, the need for methodological support of these processes, the evaluation of customers' satisfaction - this is only a part of the real proposals to implement. Systematic approach in tourism involves the creation of a risk management system in tourism enterprises, as well as a system for controlling service providers, systems of responsibility distribution. For the tourist, legislatively, tour operator is the responsible for the quality and safety, the responsibility of other parties in the law on tourist activity is not established. It is legally possible to fix the responsibility of the providers. And this proposal also follows from the theory of the systematic approach.

\section{References}

Advice from ISO/TC 176 ISO 9001 for small businesses.

Borovoi, A. A., Zhdanova, M. V., Malenchuk, Y., Pisarevsky, E. L., \& Sidorkin, S. A. (2011). Theory and practice of risk management in the tourism sector (p. 178). M.

Federal law of 27.12.2002 N 184-FZ (as amended on 23.06.2014) On technical regulation.

Goldin, A. A. (2002). The competitiveness of the tourism company: content, methods of assessment, assurance strategy (PhD thesis). St. Petersburg.

GOST R 54536-2011 Quality management systems. Cross-sectoral requirements.

GOST R 54869- 2011 Project management. Requirements for project management (p. 3).

GOST R 54871-2011 Project management. Requirements for program management.

GOST R 54985-2012 Advice from ISO/TC 176 ISO 9001 for small businesses.

ISO 10006:2003 Quality management systems -Guidelines for quality management in projects.

ISO 18091:2014Quality management systems - Guidelines for the application of ISO 9001:2008 in local government

ISO 31000:2009 Risk management - Principles and guidelines.

ISO 9001:2008 Quality management systems - Requirements.

ISO 9004:2009 Managing for the sustained success of an organization -- A quality management approach.

ISO/IEC 17020-2012 Conformity assessment. Requirements for the operation of various types of bodies performing inspection.

ISO/IEC 31010:2009 Risk management - Risk assessment techniques (pp. 12-13). 
Minko, E. V., \& Krichevsky, M. L. (2004). Quality and competitiveness (pp. 46-48). SPB.: Peter.

News of the PCT (the Russian Union of Travel Industry): PCT has prepared proposals on the bill. Retrieved October 16 , 2014 from http://rostourunion.ru/pages/rus/ob_rst/novosti/oktyabr_2014/rst_podgotovil_predlogeniya_po_zakonoproe ktu/index.html

Ogneva, S. (2009). Methodical bases of the formation of effective quality management systems in the enterprises of tourism and hotel industry. In Strategic management of socio-economic development of the tourism and recreational areas (pp. 320-352, 398-421). Monograph. M.: Moscow State Pedagogical University.

Ogneva, S. V. (2011). Monitoring of quality and safety tourist services. In National concepts of quality: experience and perspectives of innovation development (pp. 139-141). Collection of materials of scientific-practical conference. St. Petersburg.

Order of the Government of the Russian Federation of 11.11.2014 N 2246-r On approval of measures plan to implement the strategy of tourism development in the Russian Federation for the period up to 2020.

Order of the Government of the Russian Federation of 31.05.2014 N 941-p On approval of the Strategy of Tourism Development in the Russian Federation for the period up to 2020.

Pisarevsky, E. L., Borovoi, A. A., Zhdanov, M. V., Malenchuk, Y., \& Sidorkin, S. A. (2011). Tourism Security doctrine in the Russian Federation in Theory and practice of risk management in the tourism sector (pp. 163-191). M. Publishing House Lawyer.

Quality management principles. Retrieved from http://www.iso.org/iso/ru/qmp_2012.pdf

Resolution of the Government of the Arkhangelsk region on August 21, 2014 \# 337-p On Approval of the preparation of the annual report on the state of tourism development in the Arkhangelsk Region.

Resolution of the Government of the Russian Federation from 15.04.2014 \# 317 On the approval of the state program of the Russian Federation, the Development of Culture and Tourism for 2013 - 2020 years.

RIA Novosti: Suspension and bankruptcy of travel agencies in Russia. RIA Novosti, Retrieved July 16, 2014, from http://ria.ru/spravka/20140716/1016209094.html\#ixzz39VxOoGwJ.

Shadrin, A. D. (1996). Quality and Information. Standards and quality, 4, 30-33.

Sharafutdinova, E. C. (2010). Ways of improving information provision in the tourism business ( $\mathrm{PhD}$ thesis). Sochi.

The decree of the Administration of the Kostroma region on October 8, 2013 \# 403 and On approval of the report on the status, problems and prospects of tourism development in Kostroma region.

The decree of the RF Government on November 17, 2008 \# 1662-r On the Concept of Long-Term Socio-Economic Development of the Russian Federation for the period up to 2020 (with changes and updates), from http://base.garant.ru/194365/.

The law of the Samara region from 14.06.2011 \# 51-GD On state support of tourism development in Samara region.

The world economic forum: The ranking of countries in the world in terms of the competitiveness of the travel and tourism sector, 2013. The Centre for Humanitarian Technologies. Retrieved March 7, 2013, from http://gtmarket.ru/news/2013/03/07/5520

Vazovskaya, V. V., Izakova, N. B., \& Kapustina, L. M. (2014). Estimation of competitiveness of Russia on the world market of tourist services (pp. 35-43). Izvestiya UrGEU.

\section{Copyrights}

Copyright for this article is retained by the author(s), with first publication rights granted to the journal.

This is an open-access article distributed under the terms and conditions of the Creative Commons Attribution license (http://creativecommons.org/licenses/by/3.0/). 